los huevos, tanto las hembras como los machos necesitan alimentarse diariamente de azúcar; su alimento preferido es el néctar de las plantas. "Podríamos mezclar las bacterias con un néctar artificial y rociarlo sobre la vegetación", dice Dimopoulos, "o bien, podríamos desarrollar "estaciones de alimentación" para atraer a los mosquitos, para que se alimenten allí de néctar y al mismo tiempo recojan las bacterias".

Se están probando técnicas similares en otros países. En Mali, los investigadores reportaron que la aspersión de un cebo de jugo de fruta fermentado y mezclado con ácido bórico sobre las plantas redujo la población del An. gambiae en $90 \%$ en uno de los sitios del estudio. ${ }^{3}$ Por otra parte, un estudio realizado en Israel demostró que cuando se roció el agua azucarada fortalecida con el insecticida spinosad sobre los árboles frutales de los que los mosquitos solían alimentarse, prácticamente se erradicó la población de éstos. ${ }^{4,5}$

Beier señala que se requiere de más investigación para comprender el comportamiento alimentario, a base de azúcar, de los mosquitos en su estado natural, fenómeno que él mismo está estudiando. Añade que debe realizarse un esfuerzo para encontrar otras bacterias inhibidoras como las que fueron identificadas por Dimopoulos. "Me parece que es necesario demostrar cómo funcionarían estas bacterias en múltiples especies de mosquitos. Dondequiera que hay transmisión de la malaria, están presentes varias especies distintas de vectores competentes", dice.

Dimopoulos y sus colegas reportaron haber encontrado el Esp_Z únicamente en $25 \%$ de los mosquitos de la muestra. Afirma que esto puede ser un reflejo de lo caprichoso del muestreo, o que quizá no todos los mosquitos están expuestos a la bacteria, o bien, que la bacteria puede tener dificultad para colonizar el intestino del mosquito. Él y sus colegas están trabajando para ayudar a la bacteria a establecerse mejor en el interior de éste. "Por medio de múltiples rondas de selección es posible adaptar la bacteria para que logre una mejor colonización del mosquito", señala Dimopoulos.
Harvey Black, de Madison, WI, ha escrito para EHP desde 1994. Ha publicado asimismo en las revistas Environmental Science \& Technology, ChemMatters y Milwaukee Journal Sentinel.

\section{Referencias y notas}

I. Cirimotich CM, et al. Natural microbemediated refractoriness to Plasmodium infection in Anopheles gambiae. Science 332(6031):855-858 (20II); http://dx.doi.org//0.1 I26/ science. 1201618. 2. OMS.World Health Organization Media Centre Malaria Fact Sheet. Ginebra, Suiza: Organización Mundial de la Salud (abril de 2010). Disponible en: http://tinyurl.com/yolhob [consulta realizada el 27 de junio de $201 \mathrm{I}$ ].

3. Muller GC, et al. Successful field trial of attractive toxic sugar bait (ATSB) plant-spraying methods against malaria vectors in the Anopheles gambiae complex in Mali,West Africa. Malaria J 9:210 (2010); http://dx.doi.org//0.1 186/14752875-9-210.

4. Muller G, Schlein Y. Sugar questing mosquitoes in arid areas gather on scarce blossoms that can be used for control. Int J Parasitol 36(I0-II): I077-II 80 (2006); http://dx.doi. org//0.1016/j.jpara.2006.06.008.

5. Los autores observaron que al parecer otros insectos examinados en el estudio ingirieron spinosad, pero no hicieron ningún comentario sobre el modo en que se vieron afectados estos insectos.

\title{
La calidad del aire en los espacios interiores
}

\section{El impacto del cambio climático en el medio ambiente de los espacios interiores*}

$\mathrm{D}$ urante muchos años los investigadores han estado conscientes de los vínculos potenciales entre el cambio climático y la calidad del aire en los espacios exteriores. ${ }^{1}$ Son muchos menos los estudios que se han enfocado en el impacto del cambio climático en la calidad del aire en los espacios interiores. Sin embargo, un informe reciente del Instituto de Medicina (en inglés, IOM) concluye que la relación entre ambos amerita más atención y más acciones. ${ }^{2}$
"No hay muchas investigaciones sobre este tema, y se requiere de evidencias contundentes", dice John Spengler, científico ambiental de la Escuela de Salud Pública de Harvard, quien presidió el comité encargado de redactar el informe. “Este informe 
identifica la calidad del aire en los espacios interiores como una prioridad que merece ocupar un lugar importante en las investigaciones y políticas sobre el cambio climático".

La Agencia de Protección Ambiental de Estados Unidos pidió al IOM que investigara esta cuestión de manera independiente. "La mayoría de las personas pasan casi todo su tiempo en espacios interiores, de modo que es lógico que experimenten el cambio climático desde una perspectiva habitacional" , señala Patricia Butterfield, decana del Colegio de Enfermería de la Universidad Estatal de Washington, quien realizó la revisión del informe. El comité del IOM describe los cambios que pomitigar o adaptar las construcciones residenciales y comerciales al cambio climático.

Con frecuencia los planes para mitigar el cambio climático que proponen reducir las emisiones de dióxido de carbono plantean como meta reducir la cantidad de energía drían derivarse de los esfuerzos para

que se requiere para mantener un ambiente cómodo en los espacios interiores. Esto se debe a que la combustión para la producción de electricidad es una de las principales fuentes de emisiones de dióxido de carbono en Estados Unidos. ${ }^{3}$ Sin embargo, según este informe, la climatización de las construcciones para lograr un consumo de energía más eficiente podría dar lugar a nuevos problemas en los interiores, o bien, empeorar las condiciones existentes. Por ejemplo, el hecho de enmasillar y sellar las fugas en los edificios puede alterar el flujo del aire y concentrar los contaminantes propios de los interiores, como el humo de tabaco, el radón y las emisiones químicas de los materiales de construcción. ${ }^{4} \mathrm{Y}$ la humedad atrapada puede estimular el crecimiento de bacterias y moho. ${ }^{5}$

Las inclemencias climáticas representan otra posibilidad de sufrir daños en los interiores. Por ejemplo, dice Butterfield, es posible que se inunden los sótanos de los hogares o que surja moho en los desvanes

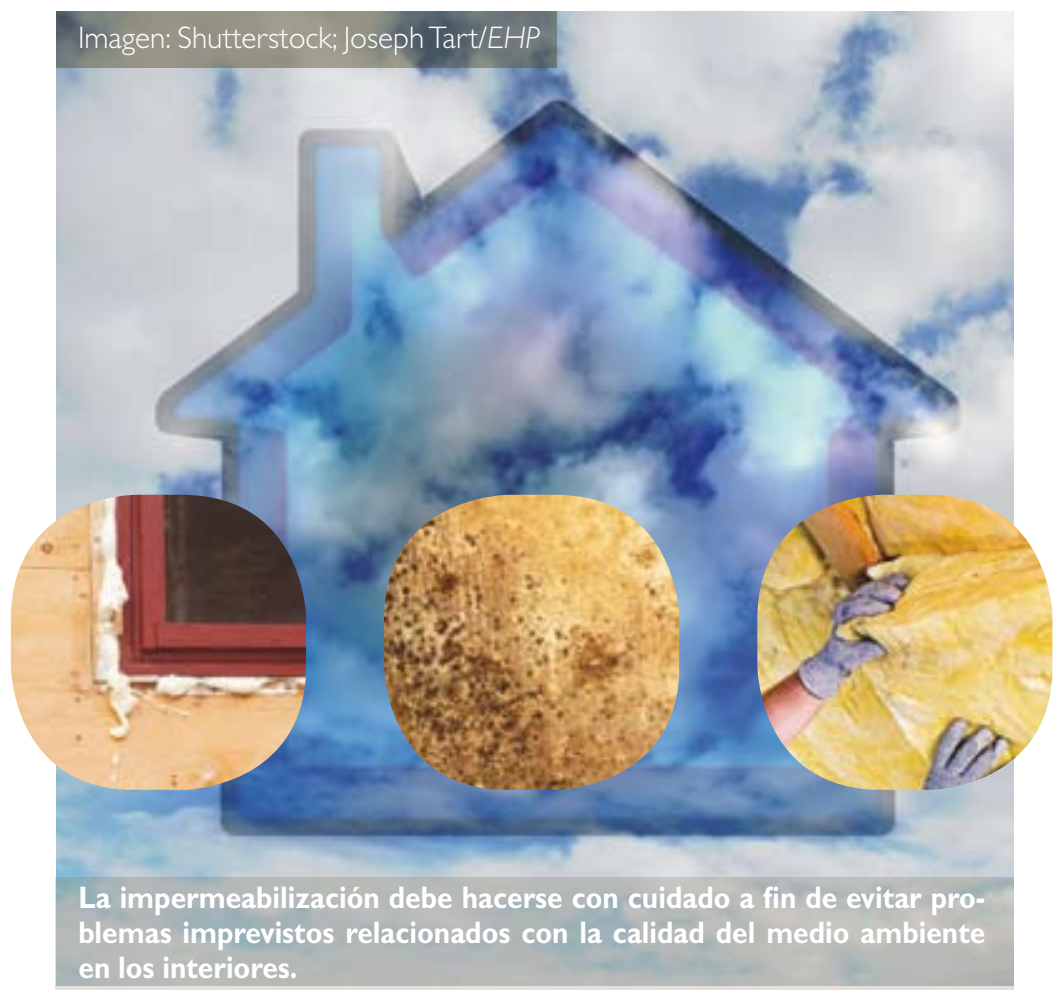

cuando se intensifican las lluvias. Asimismo, se ha atribuido un incremento de los casos de envenenamiento por monóxido de carbono después de los huracanes al uso inadecuado de generadores portátiles que funcionan con gasolina, los cuales emiten niveles elevados de dióxido de carbono. ${ }^{6}$ Cuando se hace un uso adecuado de estos generadores con una buena ventilación, no causan problemas. Sin embargo, cuando se los utiliza de manera inadecuada, cerca o dentro de los hogares, es común que las personas vayan a dar a las salas de urgencias de los hospitales o incluso mueran. "Este es un buen ejemplo de la interacción que experimentaremos a medida que nos adaptemos al cambio climático", señala Spengler. Añade que pueden introducirse en el mercado nuevos materiales y técnicas de climatización sin una previa evaluación de sus implicaciones para la salud. "Inventaremos todo tipo de cosas a medida que vayamos realizando adaptaciones para mitigar el cambio climático", explica.

Los autores del informe señalan que se requiere de una "inversión inicial" que tome en cuenta las consecuencias potenciales de las acciones de adaptación de las viviendas a fin de evitar problemas y prevenir los costos de la atención médica y la pérdida de productividad de sus ocupantes. Esta inversión podría implicar una investigación que combine datos de las dependencias del gobierno para comprender de qué manera afecta el cambio climático a la salud ambiental, implementando programas para certificar productos como útiles o no tóxicos y capacitar a los trabajadores para que instalen adecuadamente los productos de probada eficacia. Ya existen modelos para garantizar la seguridad de los materiales de construcción en los programas del Consejo para la Construcción Ecológica de EUA y Labs21.

El informe insta a las dependencias del gobierno a cooperar en 
la investigación del problema y a buscar soluciones. Varias de estas dependencias ya están reuniendo extensos conjuntos de datos, por ejemplo, mediante las encuestas sobre el consumo residencial de energía que lleva a cabo el Departamento de Energía $^{8}$ y la Encuesta Nacional de Altas Hospitalarias realizada por el Centro Nacional de Estadísticas de Salud de los Centros para el Control y Prevención de Enfermedades. ${ }^{9} \mathrm{La}$ combinación de estos datos puede ser útil para responder interrogantes sobre el modo en que el cambio climático afecta a la salud en los espacios interiores.

La identificación de los problemas complejos en materia de salud pública derivados de la relación entre el cambio climático y los ambientes en los espacios interiores puede conducir a decisiones acertadas en materia de políticas que podrían salvar vidas, comenta Butterfield. "El informe del IOM establece una conexión entre el cambio climático global y los climas extremosos y el comportamiento de las personas al intentar adaptarse a ellos", dice. "Por desgracia, muchas personas vivirán el cambio climático como un desastre natural, por ejemplo, una inundación o un huracán. Necesitamos relacionar el cambio climático global con el medio ambiente en los espacios interiores para poder proporcionarles una orientación seria".

Carol Potera, radicada en Montana, ha escrito para EHP desde 1996. Escribe también para Microbe, Genetic Engineering News y American Journal

of Nursing.

\section{Referencias y notas}

I. Penner JE, et al. Climate Change and Its Interactions with Air Chemistry: Perspectives and Research Needs. Project Summary. Washington, DC:Agencia de Protección Ambiental de EE.UU., Laboratorio de Investigaciones Ambientales y

Evaluación de la Exposición (1989).

2. Committee on the Effect of Climate Change on Indoor Air Quality and Public Health, Institute of Medicine. Climate Change, the Indoor Environment, and Health. Washington, DC:The National Academies Press (201 I). Disponible en: http://tinyurl.com/4xn4rhj [consulta realizada el 8 de agosto de 20II].

3. EPA. 201 I U.S. Greenhouse Gas Emissions. Greenhouse Gas Inventory Report [website] Washington, DC:Agencia de Protección Ambiental de EE.UU. (actualizado el 5 de agosto de 20II). Disponible en: http://tinyurl. com/ coyr8r [consulta realizada el 8 de agosto de $2011]$.

4. Letz GA. Sick building syndrome: acute illness among office workers - the role of building ventilation, airborne contaminants and work stress.Allergy Proc II (3): 109-I I6 (1990); PMID:219620I.

5. Institute of Medicine, Committee on Damp Indoor Spaces and Health. Damp Indoor Spaces and Health. Washington, DC: National Academies Press (2004). Disponible en: http://tinyurl.

com/3mmnabz [consulta realizada el 8 de agosto de 2011 ].

6. Centers for Disease Control and Prevention. Carbon monoxide poisoning after Hurricane Katrina-Alabama, Louisiana, and Mississippi, August-September 2005. MMWR 54(39):996998 (2005); PMID: 162083 I4.

7. La Agencia de Protección Ambiental y el Departamento de Energía fueron los primeros en patrocinar estas organizaciones, que actualmente operan de manera independiente. El Consejo de la Construcción Ecológica de EUA apoya a la industria de la construcción ecológica proporcionando materiales responsables, arquitectura sustentable y políticas públicas, y el programa Labs2 I promueve el diseño de laboratorios con bajo consumo de energía. 8. EIA. Residential Energy Consumption Survey (RECS) [website].Washington, DC: U.S. Energy Information Administration, U.S. Department of Energy (2009). Disponible en: http://tinyurl. com/6xpex3c [consulta realizada el 8 de agosto de 2011 ].

9. NCHS. National Hospital Discharge Survey [website]. Hyattsville, MD: Centro Nacional de Estadísticas de Salud, Centros para el Control y la Prevención de Enfermedades de EE.UU. (actualizado el $2 \mathrm{I}$ de junio de 20I I). Disponible en: http://tinyurl.com/3prz22o [consulta realizada el 8 de agosto de 20II].

\section{Contaminación ambiental y salud infantil*} Los monitores domésticos establecen conexiones cardiorrespiratorias

\begin{abstract}
L os niños son particularmente susceptibles a los efectos de la contaminación ambiental en la salud debido a que pasan más tiempo en espacios exteriores, tienen una mayor frecuencia respiratoria e inhalan un volumen mayor de aire en proporción con su peso corporal. Los bebés pueden ser especialmente
\end{abstract}

sensibles a los efectos de la contaminación ambiental porque sus sistemas inmune, respiratorio y nervioso central no están totalmente desarrollados. Hasta ahora se han estudiado mucho menos las respuestas de los bebés a la contaminación ambiental que las de los niños mayores. Un nuevo estudio establece un vínculo entre la contaminación ambiental y un incremento del riesgo de apnea (pausas prolongadas en la respiración) y bradicardia (disminución del ritmo cardiaco) en los bebés con alto riesgo de presentar estos padecimientos [EHP 119(9):1321-1327; Peel et al.]. En el estudio participaron 4277 bebés que residían en Atlanta y sus alrede-

*Publicado originalmente en Environmental Health Perspectives, volumen 119, número 9, septiembre de 2011, página A398. 